\title{
VIDEO
}

\section{Flexible endoscopic management of Zenker's diverticulum}
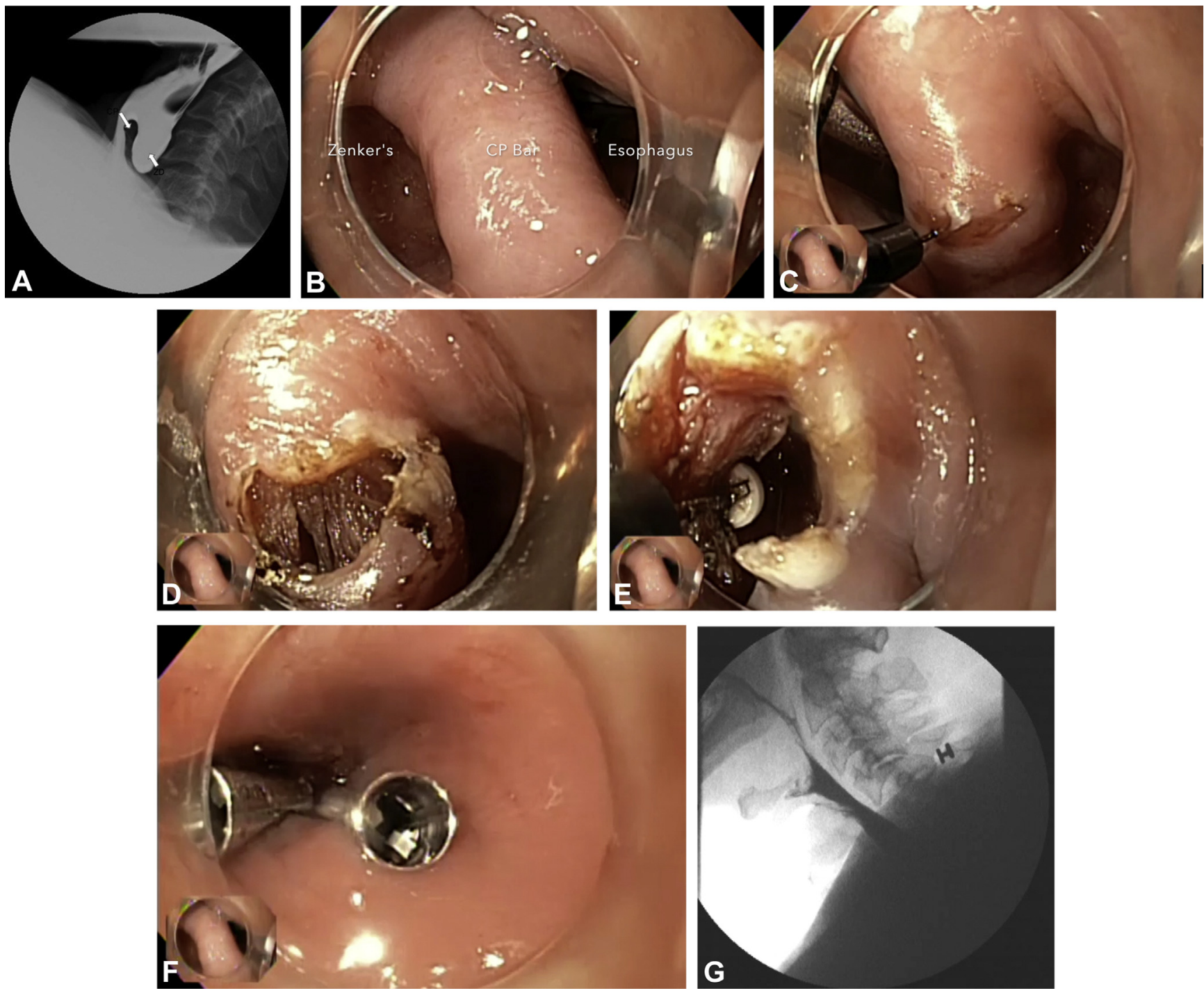

Figure 1. A, Barium esophagram revealing $Z D$ and a prominent $C P$. B, Landmark triad of $Z D$ to the left, a prominent cricopharyngeus $(C P$ bar $)$ in the middle, and the esophagus with nasogastric tube to the right. C, Needle-knife used to initially incise through prominent cricopharyngeus. D, Muscle fibers of cricopharyngeus visible after incision with the needle-knife. E, Ceramic ball insulated tip knife, which allows more controlled cutting, in use. F, Through-the-scope clips applied at base of diverticulum after cricopharyngeal incision to close any potential defects. G, Barium esophagram after myotomy revealing a small residual $Z D$. Intubation was also notably easier after myotomy. $Z D$, Zenker's diverticulum; $C P$, cricopharyngeal muscle.

A 76-year-old man was referred for a longstanding history of progressive oropharyngeal dysphagia with associated food impaction. A barium esophagram revealed Zenker's diverticulum (ZD) (Fig. 1A), and he subsequently underwent cricopharyngeal myotomy with a flexible endoscope (Video 1, available online at www.VideoGIE. org). Both flexible and rigid endoscopic myotomy are treatment modalities for $\mathrm{ZD}$; however, the flexible approach may be preferred in the elderly because there is a lower failure rate in this population, who may have limited neck extension.

Endoscopy with the patient under general anesthesia was performed. Nasogastric intubation notably was difficult, given the degree of hypertrophy of the cricopharyngeus

Written transcript of the video audio is available online at www.VideoGIE.org. 
(Fig. 1B). A nasogastric tube was successfully placed and remained in place to separate the posterior esophageal wall and diverticulum while the septum was incised. The cricopharyngeus was initially incised with a needle-knife and later with a ceramic ball insulated tip knife. The neck and chest were periodically examined for crepitus to assess for esophageal perforation. After a successful incision through the cricopharyngeus, through-the-scope clips were placed to close any potential defect between the esophagus and the diverticulum (Figs. 1C-F). A barium esophagram after the myotomy revealed a small residual ZD (Fig. 1G), with subsequent resolution of dysphagia.

Flexible endoscopic treatment of $\mathrm{ZD}$ is an effective technique, particularly in elderly patients, in whom neck extension can be difficult. Although extensive research on this subject is limited, case series have corroborated that flexible endoscopic management of ZD is effective in resolving dysphagia, with minimal procedural adverse events.

\section{DISCLOSURE}

All authors disclosed no financial relationships relevant to this publication.

Chaitanya Allamneni, MD, Department of Internal Medicine, William Ergen, MD, Division of Gastroenterology and Hepatology, Department of Medicine, Stewart Herndon, BS, University of Alabama School of Medicine, Frederick Weber, MD, Kondal Kyanam Kabir Baig, MBBS, Division of Gastroenterology and Hepatology, Department of Medicine, University of Alabama at Birmingham, Birmingham, Alabama, USA

Copyright (c) 2018 American Society for Gastrointestinal Endoscopy. Published by Elsevier Inc. This is an open access article under the CC BY-NC-ND license (http://creativecommons.org/licenses/by-nc-nd/4.0/).

https://doi.org/10.1016/j.vgie.2017.10.002

\section{Twitter}

Become a follower of VideoGIE on Twitter. Learn when new articles are posted and receive up-to-the-minute news as well as links to our latest videos. Search @VideoGIE on Twitter. 